\title{
Evaluation of the Electrocardiographic Parameters of Anemic Children Before and After Anemia Correction
}

\author{
Mehmet Uğurlu (D, Münevver Tuğba Temel (D) \\ Department of Pediatrics, Faculty of Medicine, University of Gaziantep, Gaziantep, Turkey
}

ORCID iDs of the authors: M.U. 0000-000I-6925-5026; M.T.T. 0000-000I-8636-664I.

Cite this article as: Uğurlu M, Temel MT. Evaluation of the Electrocardiographic Parameters of Anemic Children Before and After Anemia Correction. Cyprus J Med Sci 2020; 5(3): 221-5.

\section{BACKGROUND/AIMS}

Iron deficiency is the most common and widespread nutritional disorder, which leads to iron deficiency anemia (IDA) if left untreated. IDA can present in various forms with the involvement of multiple systems, varying from arrhythmia to left ventricular dysfunction and even heart failure in cardiological terms. Nowadays, electrocardiography (ECG) is the most accessible and valuable method of diagnosing rhythm and conduction disorders. In this study, we aimed to evaluate the ECG parameters, such as QT, QTc, QT dispersion, Tp-e interval, and Tp-e/QTc ratio used in the diagnosing malignant ventricular arrhythmias, of children before and after IDA treatment.

\section{MATERIAL and METHODS}

This study included 30 children with no cardiac or chronic disease and was conducted between December 2017 and June 2018 . All the children were diagnosed with IDA and treated in the Pediatrics Outpatient Clinics of Gaziantep University Medical Faculty. Pre- and post-treatment QT, QTc, Tp-e interval, Tp-e/QTc ratio, and QT dispersion values of the patients were compared.

\section{RESULTS}

Post-treatment values of hemoglobin, mean corpuscular volume, Ferritin, and Fe were significantly lower than the pretreatment values, while total iron-binding capacity was found to be significantly higher. The QTc, Tp-e interval, and Tp-e/QTc ratio were significantly lower after the treatment.

\section{CONCLUSION}

Our study revealed that QTc, Tp-e interval, and Tp-e/QTc ratios on the ECG decreased after treatment of the IDA. Children diagnosed with IDA should be carefully monitored for ventricular arrhythmias throughout the treatment.

Keywords: Iron deficiency anemia, electrocardiography, childhood

\section{INTRODUCTION}

Iron deficiency is the most common and widespread nutritional disorder, which leads to iron deficiency anemia (IDA) if left untreated (I). IDA can either be asymptomatic or present with the involvement of multiple systems. In terms of cardiovascular manifestation, patients who are diagnosed with IDA can have a clinical picture varying from arrhythmia to left ventricular dysfunction, and even heart failure (2).

Electrocardiography (ECG) is still the most valuable method because it is an inexpensive, accessible, and non-invasive technique used in the diagnosis of rhythm and conduction disorders. Studies commonly investigate new ECG parameters like Tp-e interval, Tp-e/QTc ratio as well as QT and QT, showing ventricular repolarization abnormalities in the diagnosis of malignant ventricular arrhythmias, which is a leading cause of sudden cardiac death $(3,4)$. It is known that sudden cardiac death can occur without an underlying heart disease. On this basis, the relationship between anemia and ventricular arrhythmias is frequently studied in both pediatric and adult patients. The relationship between IDA and electrocardiographic measurements in children has also been a subject of various studies, and previous studies have shown that anemia prolongs the values of Tp-e interval, Tp-e/QTc ratio, as well as QT and QTc $(5,6,7)$. However, to the best of our knowledge, no study has compared the pre- and post-treatment ECG values of patients with IDA. In our study, we aimed to compare pre- and post-treatment QT, QTc, Tp-e interval, Tp-e/QTc ratio, and QT dispersion in children 

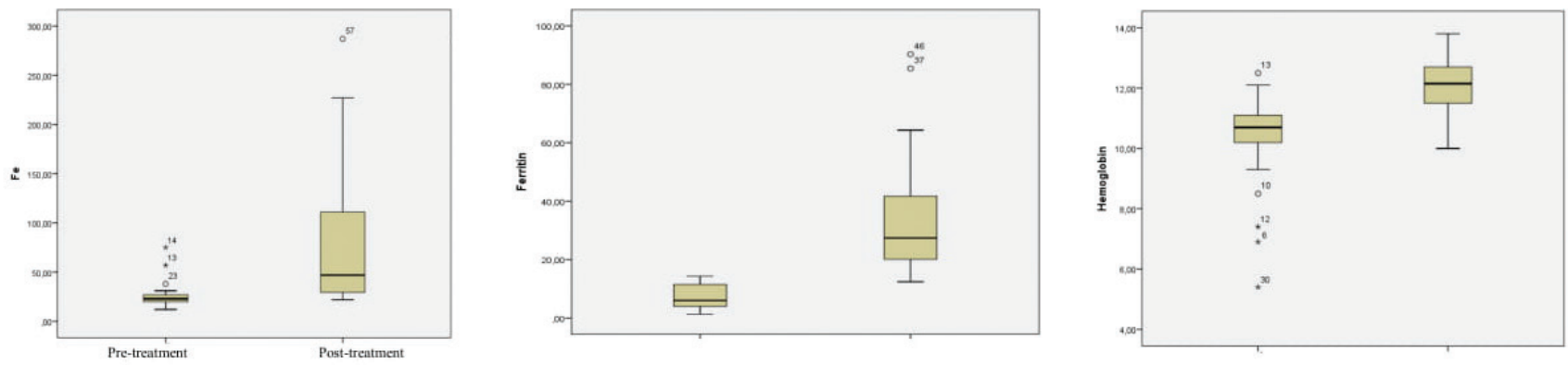

FIGURE I. Comparison of the hematologic parameters of the groups

diagnosed with IDA for the early diagnosis of life-threatening arrhythmias during treatment.

\section{MATERIAL and METHODS}

This prospective study involving 30 children diagnosed with IDA was conducted at the Pediatrics outpatient clinic of Gaziantep University Faculty of Medicine between December 2017 and June 2018. The patients consisted of children who consulted to our hospital because of their incidental anemias. Patients with an underlying congenital or rheumatologic heart disease and chronic disease, as well as those with ventricular dysfunction, arrhythmia, hypo-hyperthyroidism, electrolyte imbalance, or acute inflammatory disease, or patients receiving drug therapy were excluded from the study because it may affect the ECG parameters. Detailed physical examinations and 12-derivation ECG as well as the full blood count, serum electrolytes, urea, creatinine, iron, ferritin, and total iron-binding capacity (TIBC) values of these patients, were examined. Hemoglobin electrophoresis from each patient was also examined for the differential diagnosis of IDA. A $6 \mathrm{mg} / \mathrm{kg} /$ day ferrous sulfate treatment was administered to the IDA patients for 12 weeks. ECG measurements were repeated after the treatment in the patients whose anemia was corrected, and the results were compared to pretreatment results. Voluntary informed consent was obtained from the patients/parents and presented to the Ethics Committee. This study was conducted in line with the approval obtained by the decision of Gaziantep University Clinical Trials Ethics Committee dated 06.06.2018 and numbered 2018/92.

\section{Electrocardiography}

Standard I2-derivation ECGs of the patients were recorded at rest in the supine position with an amplitude of $\mathrm{I} \mathrm{V} / \mathrm{cm}$ and speed of

\section{Main Points:}

- Iron deficiency is the most common and widespread nutritional disorder, which leads to iron deficiency anemia in children

- Iron deficiency anemia can present in various forms with the involvement of multiple systems, varying from arrhythmia to left ventricular dysfunction and even heart failure in cardiological terms.

- Patients with iron deficiency anemia should be followed-up for life-threatening arrhythmias during treatment
25 mm/sec (Mortara ELI 280; Nihon Kohden, Tokyo, Japan). The electrocardiographic records were transferred to a computer via scanners and computerized to obtain more meticulous measurements. QT interval was defined as the time from the onset of the QRS complex to the point of the T wave's return to the isoelectric line. The deepest point between the $T$ and $U$ waves was measured in the presence of the $U$ wave. Electrocardiographic records were considered analyzable when a $T$ wave was available in eight or more electrodes. QT interval was not measured in the absence of the T wave. Since QT interval varies with the heart rate, QTc was calculated using Bazett's formula (8). QT interval was measured in all the available leads, including lead I, II, and $\checkmark 5$ in particular. The mean value of three measurements of the QT interval was used for further analysis. The difference between the longest and the shortest QT interval was calculated as the QT dispersion (QTd). Tp-e interval was measured from $T_{\text {peak }}$ (the highest point of $T$ wave) to $T_{\text {end }} T_{\text {end }}$ was defined as the intersection point between the tangent point of the downward slope of the T wave and the isoelectric line. U wave was ignored. Tp-e/ QTC ratio was calculated from these measurements. All the Tp-e measurements were performed in the precordial leads.

\section{Iron Deficiency Anemia}

Iron (Fe), ferritin, TIBC, hemoglobin ( $\mathrm{Hb}$ ), hematocrit ( $\mathrm{Hct}$ ), and mean corpuscular volume (MCV) values of all the patients were studied for the assessment of the diagnosis and treatment of IDA. Hb values -2SD below the age-appropriate levels and ferritin values below $15 \mathrm{ng} / \mathrm{mL}$ were taken into account for the diagnosis of IDA (9).

\section{Statistical Analysis}

The data obtained were analyzed using the SPSS (Statistical Package for the Social Sciences) version 22 statistical package software (IBM SPSS Corp.; Armonk, NY, USA). The Mann-Whitney $U$ test, independent groups Student's t-test, dependent groups t-test, Wilcoxon test, and Pearson correlation analyses were used together with descriptive statistics. Mean, standard deviation, lowest, and highest values were used and expressed in tables and graphics for the descriptive statistics. The level of significance was accepted as 0.05 .

\section{RESULTS}

This study included 30 patients who were diagnosed with and treated for IDA. The mean age of the patients was 4.8 \pm 4.4 . Nineteen patients were males, and II were females. Comparison of the pre- and post-treatment hematological parameters of the 

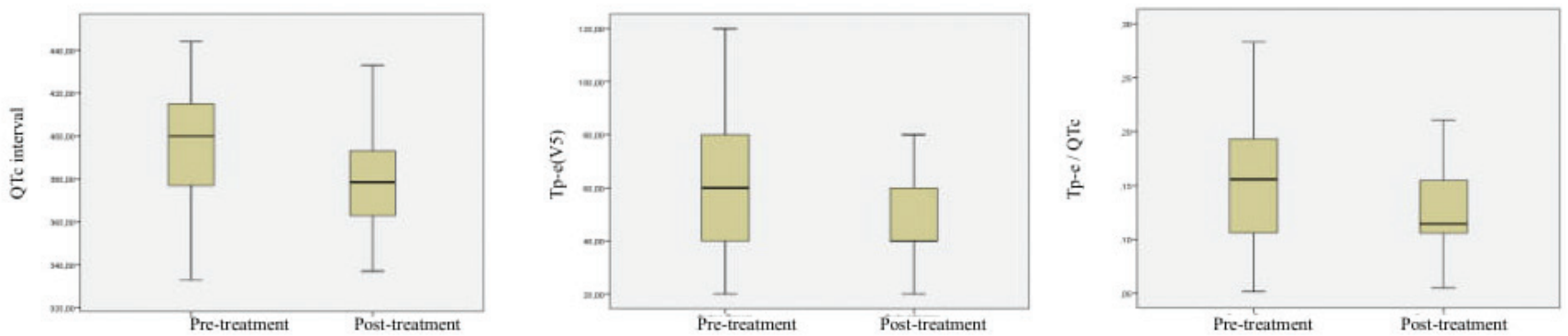

FIGURE 2. Comparison of the electrocardiographic parameters of the groups

TABLE I. Comparison of the hematologic parameters of the groups. RBC red blood cells, MCV mean cell volume, Fe iron, TIBC total iron-binding capacity

\begin{tabular}{|c|c|c|c|c|c|}
\hline \multirow[b]{2}{*}{ Hematologic Parameters } & \multicolumn{2}{|c|}{ Pre-treatment } & \multicolumn{2}{|c|}{ Post-treatment } & \multirow[b]{2}{*}{$P$ value } \\
\hline & Mean \pm SD & Minimum - Maximum & Mean \pm SD & Minimum - Maximum & \\
\hline Hemoglobin (g/dl) & $10.3 \pm 1.6$ & $5.4-12.5$ & $12.1 \pm 0.9$ & $10.0-13.8$ & 0.000 \\
\hline$M C \vee(f L)$ & $69.1 \pm 6.0$ & $52.0-79.6$ & $75.0 \pm 4.7$ & 68.1-87.7 & 0.000 \\
\hline Ferritin (ug/L) & $7.5 \pm 4.1$ & $1.3-14.3$ & $33.8 \pm 20.0$ & $12.4-90.3$ & 0.000 \\
\hline $\operatorname{TIBC}(\mu \mathrm{g} / \mathrm{dl})$ & $4 \mid 2.1 \pm 55.9$ & $331.0-572.0$ & $348.7 \pm 54.6$ & $256.0-509.0$ & 0.000 \\
\hline
\end{tabular}

TABLE 2. Comparison of the electrocardiographic parameters of the groups. bpm beat per minute, ms milliseconds, QTc corrected QT interval

\begin{tabular}{|c|c|c|c|c|c|}
\hline \multirow[b]{2}{*}{ Electrocardiographic Parameters } & \multicolumn{2}{|c|}{ Pre-treatment } & \multicolumn{2}{|c|}{ Post-treatment } & \multirow[b]{2}{*}{$P$ value } \\
\hline & Mean $\pm S D$ & Minimum - Maximum & Mean \pm SD & Minimum - Maximum & \\
\hline Heart rate (bpm) & $118.0 \pm 29.8$ & $72.0-171.0$ & $109.3 \pm 25.5$ & $73.0-153.0$ & 0.054 \\
\hline QTc (ms) & $396.6 \pm 29.4$ & $333.0-444.0$ & $381.6 \pm 24.4$ & $337.0-433.0$ & 0.010 \\
\hline Tp-e (V5) (ms) & $61.3 \pm 22.2$ & $20.0-120.0$ & $50.0 \pm 14.6$ & $20.0-80.0$ & 0.001 \\
\hline Tp-e (V5) / QTc & $0.2 \pm 0.1$ & $0.1-0.3$ & $0.1 \pm 0.0$ & $0.1-0.2$ & 0.002 \\
\hline
\end{tabular}

30 patients is shown in Table I and Figure I. Compared to the post-treatment values, $\mathrm{Hb}, \mathrm{MCV}$, Ferritin, and Fe values were significantly lower while TIBC was significantly higher. Comparison of the pre- and post-treatment electrocardiographic parameters of the patients is shown in Table 2 and Figure 2. When compared to the pretreatment values, it was found that QTc interval, Tp-e interval, and Tp-e/QTc ratio were significantly decreased after the treatment.

\section{DISCUSSION}

This study showed that QTc, Tp-e interval, and Tp-e/QTc ratio values were significantly decreased after treatment in patients whose IDA was corrected. Our study also found a negative correlation between QTc and both $\mathrm{Hb}$ and Ferritin ( $\mathrm{Hb}$ : $r=-0,24$ $p=0,193$; Ferrritin: $r=-0,133 p=0,484$ ). Studies, particularly in the adult literature have shown that IDA is correlated with cardiomyopathy, left ventricular dysfunction, and premature ventricular contractions $(7,10)$. However, similar studies are limited among pediatric patients.
QT interval defines ventricular depolarization and repolarization, and a prolonged QT interval increases the risk of fatal ventricular arrhythmia and sudden cardiac death (II). Studies have shown prolonged QTc intervals in patients with renal failure and thalassemia, resulting in high Fe stores $(12,13)$. Similarly, several studies on pediatric and adult patients with sickle cell anemia in the USA showed QT interval prolongations (14-16). However, another study on anemia patients with different etiological causes found normal QT intervals in anemia patients (17). A study by Karadeniz et al. (18) on pediatric patients with anemia demonstrated a negative correlation between ferritin levels and QTC. In our study, we showed that the QTC values of patients whose IDA was corrected with treatment were significantly decreased compared to the pretreatment values. There was a negative correlation between ferritin and $\mathrm{Hb}$ values and QTC. Different results in the literature might be attributed to the different etiologies of anemia and the different measuring techniques. Similar results in diseases that present with both anemia and high $\mathrm{Fe}$ stores might be due to the fact that iron is a significant element in the enzymatic system of cardiomyocytes. 
QT dispersion is defined as the difference between the longest and shortest QT distance in a 12-derivation ECG. This difference between QT distances indicates a non-uniform ventricular repolarization, and as it prolongs, it may lead to the development of severe ventricular arrhythmia, which can result in sudden cardiac death, like in long QT interval $(19,20)$. Since there is no consensus on the pathological upper limit of the reference intervals and values, the relationship of QTd with cardiac mortality is controversial, but various studies argue otherwise. In a study by Kulanet al. on patients with MVP, QTc dispersion was found to be higher than in the control group (2I). In a study by Karadeniz et al. (I8) on pediatric patients, QTC dispersion was found to be significantly higher in patients with low iron stores, while it had a significantly negative correlation with ferritin. In our study, we did not find a significant difference between preand post-treatment values. The differences in studies might be due to the different measuring techniques and the difficulty in determining the endpoint of the T wave.

The distance between the peak point and endpoint of the $T$ wave is defined as the Tp-e interval, and it is a measure of the transmyocardial distribution of ventricular repolarization. Prolongation of Tp-e interval might be associated with dangerous rhythm disorders and ventricular arrhythmias (3). However, various studies showed that the Tp-e/QTc ratio could reveal ventricular repolarization abnormalities more precisely because it is not affected by the heart rate and body mass index (22). Tp-e/ QTC ratio was found to be higher in patients with the risks of an arrhythmogenic condition, such as long QT syndrome, Brugada syndrome, acute myocardial infarction, and short QT syndrome $(3,23,24)$. In our study, we showed that both the Tp-e interval and Tp-e/QTc ratio were significantly higher in children before the treatment. We also found a negative correlation between post-treatment $\mathrm{Hb}$ and both $\mathrm{Tp}-\mathrm{e}$ interval and $\mathrm{Tp}-\mathrm{e} / \mathrm{QTc}$ ratio ( $\mathrm{Hb}$ and Tp-e interval: $r=0,179 \mathrm{p}=0,343 \mathrm{Hb}$ and $\mathrm{Tp}-\mathrm{e} / \mathrm{QTc}$ ratio: $r=0,266 p=0,155)$.

The impact of anemia and iron deficiency on cardiovascular hemodynamics has been demonstrated in several studies $(25,26)$. Iron is stored in cells as an important element of the enzymatic system of cardiomyocytes. Many studies reported that cardiovascular hemodynamics were affected in both iron deficiency and iron overload secondary to chronic blood transfusions (2, $27,28)$.

These studies compared patient groups with and without anemia and revealed that anemia caused myocardial diseases by affecting the increased cardiac output, increased sympathetic activation, and ventricular functions $(28,29)$. To the best of our knowledge, our study is the first one that was conducted with dependent variables, differently from other studies. In our study, we compared the cardiac functions of patients with corrected anemia to the pretreatment values. The study showed that QTc, Tp-e interval, and Tp-e/QTc ratio values were significantly decreased after treatment in patients whose IDA was corrected. Low $\mathrm{Hb}$ levels were considered to reduce the systemic vascular resistance by decreasing the blood viscosity (30). In this context, decreased myocardial tissue oxygenation in iron deficiency anemia and the accompanying autonomic imbalance might be a potential reason for the higher QTc, Tp-e interval, and Tp-e/ QTC ratio measures before the treatment.
Our study had some limitations. The primary limitation was the small sample size, restricts the strength of detecting small differences. Secondly, our patients were anemic children with low iron stores. It would be beneficial to conduct a comparison study with patients who have low iron stores but have not yet developed anemia.

In conclusion, our study showed that the QTc, Tp-e interval, and Tp-e/QTc ratios decreased on the ECG after the iron deficiency anemia was treated. Therefore, these parameters, which have been used as new markers for predicting atrial and ventricular arrhythmias in many studies, should also be carefully evaluated in children with iron deficiency, and patients should be followed-up for life-threatening arrhythmias during treatment. However, additional studies, including more extensive series and different multicenter units, are needed in this regard.

Ethics Committee Approval: Ethics committee approval was received for this study from the ethics committee of Gaziantep University (06.06.2018/92).

Informed Consent: Written informed consent was obtained from the patients who participated in this study.

Peer-review: Externally peer-reviewed.

Author contributions: Concept - M.T.T.; Design - M.T.T; Supervision M.T.T; Resource - M.T.T. M.U.; Materials - M.U.; Data Collection and/ or Processing - M.U.; Analysis and/or Interpretation - M.U.; Literature Search - M.T.T.; Writing - M.T.T; Critical Reviews - M.T.T.

Acknowledgements: Thanks to Assist. Prof. Dr. Fatma Yılmaz Coșkun, M. D. from Cardiology department for helping the measurements of electrocardiographies.

Conflict of Interest: Authors have no conflicts of interest to declare.

Financial Disclosure: The authors declared that this study has received no financial support.

\section{REFERENCES}

I. Camaschella C. New insights into iron deficiency and iron deficiency anemia. Blood Reviews 2017; 3I(4): 225-33. [Crossref]

2. Jankowska EA, Ponikowski P. Molecularchanges in myocardium in the course of anemia or iron deficiency. Heart Fail Clin 2010; 6(3): 295-04. [Crossref]

3. P. Gupta, C. Patel, H. Patel, S. Narayanaswamy, B. Malhotra, J.T. Green, et al. T pe/QT ratio as an index of arrhythmogenesis. J Electrocardiol 2008; 4I(6): 567-74. [Crossref]

4. Okin PM, Devereux RB, Howard BV, Fabsitz RR, Lee ET, WeltyTK. Assessment of QT interval and QT dispersion for predictionof allcause and cardiovascular mortality in AmericanIndians: The Strong Heart Study. Circulation 2000; I0I(I): 61-6. [Crossref]

5. Kikuchi $M$, Inagaki $T$. Atrial natriuretic peptide in aged patients with iron deficiency anemia. Arch Gerontol Geriatr 1999; 28(2): 105-15. [Crossref]

6. Mehta BC, Panjwani DD, Jhala DA. Electrophysiologic abnormalities of heart in iron deficiency anemia. Effect of iron therapy. Acta Haematol 1983; 70(3): 189-93. [Crossref]

7. Hegde N, Rich MW, Gayomali C. The cardiomyopathy of iron deficiency. Tex Heart Inst J 2006; 33(3): 340-44.

8. Bazett HC. An analysis of the time relations of electrocardiograms. Heart 1920; 7: 353-70.

9. Sills R. Nelson textbook of pediatrics. In: Kliegman R.M editor. Iron deficiency anemia. Philadelphia; 2016; 20: 2323-26.

10. Venkateswaran RV, Freeman C, Chatterjee N, Kandala J, Orencole $M, V e g h E M$, et al. Anemia and its association with clinical outcome 
in heart failure patients undergoing cardiac resynchronization therapy. J Interv Card Electrophysiol 2015; 44(3): 297-04. [Crossref]

II. Farahani B, Abbasi M, Khaheshi I, Paydary K. "Evaluation of QT interval in $b$ thalassemia major patients in comparison with control group." Heart views 2012; 13(2): 42-5. [Crossref]

12. Bavbek N, Yilmaz H, Erdemli HK, Selcuki Y, Duranay M,Akçay A. Correlation between iron stores and QTc dispersionin chronic ambulatory peritoneal dialysis patients. Ren Fail 2014; 36(2): 187-90. [Crossref]

13. Faruqi A, Ahmad SI, Ahmed ST. Evaluation of QT parameters in patients of thalassaemia major with iron overload. J Pak Med Assoc 2016; 66: 799-02.

14. Holloman KL, Johnson CS, Haywood LJ. Electrocardiogram analysis in adult patients with sickle cell disease. J Natl Med Assoc 1987; 79(8): 809-14.

15. Oguanobi NI, Onwubere BJ, Ike SO, Anisiuba BC, Ejim EC, Ibegbulam OG. Electocardiographic findings in adult Nigerians with sickle cell anaemia. Afr Health Sci 20I0; 10(3): 235-4I [Crossref].

16. Mueller BU, Martin KJ, Dreyer W, Bezold LI, Mahoney DH. Prolonged QT interval in pediatric sickle cell disease. Pediatr Blood Cancer 2006; 47(6): 83I-3. [Crossref]

17. Fei YD, Li YG, Surkis W, Zhang L. Does Anemia Cause QT Prolongation in Patients with Hematologic Disorders? Chinese medical journal. 2015; 128(24): 3385-86. [Crossref]

18. Karadeniz C, Özdemir R, Demirol M, Katipoğlu N, Yozgat Y, Meșe T, et al. Low iron stores in otherwise healthy children affect electrocardiographic markers of important cardiac events. Pediatr Cardiol 2017; 38(5): 909-14. [Crossref]

19. Antzelevitch C, Sicouri S, Di Diego JM, Burashnikov A, Viskin S, Shimizu W, et al. Does Tpeak-Tend provide an index of transmural dispersion of repolarization? Heart Rhythm 2007; 4(8): III4-6. [Crossref]

20. Yuan S, Wohlfart B, Olsson SB, Blomström-Lundqvist C. The dispersion of repolarization in patients with ventricular tachycardia: a study using simultaneous monophasic action potential recordings from two sites in the right ventricle. Eur Heart J 1995; 16(I): 68-76. [Crossref]

21. Zouridakis EG, Parthenakis FI, Kochiadakis GE, Kanoupakis EM, Vardas PE. QT dispersion in patients with mitral valve prolapse is related to the echocardiographic degree of the prolapse and mitral leaflet thickness. Europace 200I; 3(4): 292-8. [Crossref]

22. Akın A, Unal E, Yıldııım R, Ture M, Balık H, Haspolat YK. Evaluation of QT dispersion and Tp-e interval in children with subclinical hypothyroidism. Pacing Clin Electrophysiol 2018; 4I(4): 372-5. [Crossref]

23. C.J.Boos, E. Vincent, A. Mellor, D.R. Woods, C. New, R. Cruttenden, et al. The effect of high altitude on central blood pressure and arterial stiffness. J Hum Hypertens 20I7; 3I(II): 715-9. [Crossref]

24. Hevia JC, Antzelevitch C, Barzaga FT, Sanchez MD, Balea FD, Molina RZ, et al. Tpeak-tend and Tpeak-tend dispersion as risk factors for ventricular tachycardia/ventricular fbrillation in patients with the Brugada syndrome. J Am Coll Cardiol 2006; 47(9): 1828-34. [Crossref]

25. Jankowska EA, Ponikowski P. Molecularchanges in myocardium in the course of anemia or irondeficiency. Heart Fail Clin 2010; 6(3): 295-304. [Crossref]

26. Sarnak MJ, Tighiouart H, Manjunath G, MacLeod B, Griffith J, Salem $D$, et al. Anemia as a risk factor for cardiovascular disease in the atherosclerosis risk in communities (ARIC) study. J Am Coll Cardiol 2002; 40(I): 27-33. [Crossref]

27. Tanimura, M. Dohi K, Fujimoto N, Moriwaki K, Omori T, Sato Y, et al. Effect of Anemia on Cardiovascular Hemodynamics, Therapeutic Strategy and Clinical Outcomes in Patients with Heart Failure and Hemodynamic Congestion. Circulation journal: official journal of the Japanese Circulation Society 2017; 8I(II): 1670-7. [Crossref]

28. Faruqi A, Ahmad SI, Ahmed ST. Evaluation of QT parameters in patients of thalassaemia major with iron overload. J Pak Med Assoc 2016; 66(7): 799-802.

29. Turner LR, Premo DA, Gibbs BJ, Hearthway ML, Motsko M, Sappington $A$, et al. Adaptations to iron deficiency: cardiac functional responsive- ness to norepinephrine, arterial remodeling, and the effect of beta-blockade on cardiac hyper- trophy. BMC Physiol 2002; 2: I. [Crossref]

30. Metivier F, Marchais SJ, Guerin AP, Pannier B, London GM. Pathophysiology of anaemia: Focus on the heart and blood vessels. Nephrol Dial Transplant 2000; 15(3): 14-8. [Crossref] 